\title{
Job Resources and Matching Active Coping Styles as Moderators of the Longitudinal Relation Between Job Demands and Job Strain
}

\author{
Marieke van den Tooren • Jan de Jonge • \\ Peter Vlerick • Kevin Daniels • Bart Van de Ven
}

Published online: 2 March 2011

(C) The Author(s) 2011. This article is published with open access at Springerlink.com

\begin{abstract}
Background Only in a few longitudinal studies it has been examined whether job resources should be matched to job demands to show stress-buffering effects of job resources (matching hypothesis), while there are no empirical studies in which the moderating effect of matching personal characteristics on the stress-buffering effect of job resources has been examined.

Purpose In this study, both the matching hypothesis and the moderating effect of matching active coping styles were examined with respect to the longitudinal relation between job demands, job resources, and job strain.

Method The study group consisted of 317 beginning teachers from Belgium. The two-wave survey data with a 1-year time lag were analyzed by means of structural equation modeling and multiple group analyses.

Results Data did not support the matching hypothesis. In addition, no support was found for the moderating effect of specific active coping styles, irrespective of the level of match.

Conclusion To show stress-buffering effects of job resources, it seems to make no difference whether or not specific
\end{abstract}

\footnotetext{
M. van den Tooren $(\bowtie) \cdot J$. de Jonge

Department of Industrial Engineering and Innovation Sciences,

Human Performance Management Group,

Eindhoven University of Technology,

P.O. Box 513, 5600 MB Eindhoven, The Netherlands

e-mail: M.v.d.Tooren@tue.nl

P. Vlerick $\cdot$ B. Van de Ven

Ghent University,

Ghent, Belgium

K. Daniels

Loughborough University Business School,

Loughborough, UK
}

types of job demands and job resources are matched, and whether or not individual differences in specific active coping styles are taken into account.

Keywords Job demands and job resources - Active coping styles $\cdot$ Match $\cdot$ Job stress $\cdot$ Burnout $\cdot$ Teachers

\section{Introduction}

Research in job stress has concentrated on identifying characteristics of the work environment that may relate to worker's health and well-being. One dominant approach in this domain proposes that health and well-being can be explained by two distinct classes of job characteristics: job demands and job resources [1]. Job demands are workrelated tasks that require effort, and vary from solving complex problems to dealing with aggressive clients or lifting heavy objects. Job resources on the other hand, are work-related assets that can be employed to deal with job demands. Examples of job resources are job autonomy, emotional support from colleagues, and technical equipment.

Several researchers have pointed out the stress-buffering effect of job resources on the relation between job demands and job strain (e.g., [2-4]). Specifically, it has been proposed that high job demands will have a deleterious impact on worker's health and well-being unless workers have sufficient job resources to deal with their demanding job. Job resources may be particularly likely to operate as a stress buffer if they are matched to job demands. That is, if workers use job resources that belong to the same domain of functioning as the type of job demands they need to deal with (e.g., [5, 6]). This idea of match is often referred to as the 'matching hypothesis' [7] and is accompanied by a sound body of empirical evidence (cf. [8]). However, to this very 
moment, the matching hypothesis has mainly been tested in cross-sectional studies [8]. Because cross-sectional designs are not well-suited to make causal inferences about the relation between demands, resources, and strain [9], it seems of great interest to extend the number of longitudinal studies on the matching hypothesis. Therefore, the first aim of the current study is to examine the matching hypothesis with respect to the longitudinal relation between job demands, job resources, and job strain. In this study, we will use a time lag of 1 year to control for time-variant effects (e.g., seasonal fluctuations) that might be present when using time lags shorter than 1 year (cf. $[10,11])$. Moreover, compared to time lags of more than 1 year (i.e., 2 or 3 years), a 1 -year time lag has proven to be most appropriate for demonstrating longitudinal stressor-strain relations [12].

In addition to the match between job demands and job resources, stress-buffering effects of job resources may also depend on worker's personal characteristics. Specifically, it has been argued that personal characteristics are likely to moderate the linkage between job conditions and job strain [13]. An individual characteristic that could particularly moderate the stress-buffering effect of job resources is worker's active coping style. Active coping style can be defined as a persistent tendency to actively manage critical events that pose a challenge, threat, harm, loss, or benefit to a person (cf. $[14,15])$. If we translate this definition to work settings, it follows that workers with a high active coping style are more inclined to actively cope with job demands than workers with a low active coping style (cf. [16-19]). Because active coping behavior in demanding situations at work implies the investment of job resources, it seems reasonable to assume that differences in active coping style will have a different impact on the activation of job resources in stressful situations at work. That is, in case of high job demands, workers with a high active coping style may be more likely to activate job resources than workers with a low active coping style (cf. [20]). For instance, workers with a high active coping style may be more likely to consult an expert in the field, ask for emotional support, or employ technical equipment. Because workers who activate job resources are generally more likely to benefit from the stressbuffering effect of job resources than workers who do not use job resources, individual differences in active coping style should be expressed in the number of stress-buffering effects of job resources that are found for the individuals involved. In a cross-sectional study by de Rijk et al. [18], it was indeed shown that high (vs. low) active coping style has a synergistic effect on the stress-buffering effect of job resources. The second aim of the current study was to examine the moderating effect of worker's active coping style on the lagged stress-buffering effect of job resources.

Several researchers have suggested that the moderating effect of active coping style will be stronger if the nature of coping is specific to job resources (cf. [21, 22]). In other words, to show stronger moderating effects of active coping style on the stress-buffering effect of job resources, active coping style should belong to the same domain of functioning as job resources. To the best of our knowledge, the moderating effect of specific, corresponding types of active coping styles has not been tested yet. Therefore, the third aim of the current study is to examine the moderating effect of matching active coping styles with respect to the longitudinal relation between job demands, job resources, and job strain.

\section{Matching Hypothesis}

According to the matching hypothesis, specific types of job resources should be matched to specific types of job demands to show stress-buffering effects of job resources (e.g., [5, 23]). Generally speaking, three specific types of job demands and job resources can be distinguished: cognitive, emotional, and physical demands and resources $[24,25]$. When the matching hypothesis is applied to the longitudinal relation between job demands, job resources, and job strain, it follows that workers who are faced with high cognitive job demands (e.g., solving complex problems) at a certain moment in time, are least likely to experience job strain (e.g., mental fatigue) 1 year later if they have sufficient cognitive job resources (e.g., information from handbooks) to deal with their cognitively demanding job. Similarly, workers who are confronted with high emotional job demands (e.g., feeling threatened by aggressive patients) at a certain moment in time, are least likely to experience job strain (e.g., emotional exhaustion) 1 year later if they have sufficient emotional job resources (e.g., a listening ear from colleagues) to deal with their emotionally demanding job. Finally, if workers are faced with high physical job demands (e.g., moving heavy objects) at a certain moment in time, they are least likely to experience job strain (e.g., back pain) 1 year later if they have sufficient physical job resources (e.g., a trolley) to deal with their physically demanding job [25, 26]. This brings us to the following hypothesis:

Hypothesis 1 Stress-buffering effects of job resources on the longitudinal relation between job demands and job strain are more likely to occur if there is a match between specific types of job demands and job resources than if there is a non-match between specific types of job demands and job resources.

\section{Matching Active Coping Styles}

As explained before, workers with a high active coping style are more likely to activate job resources in demanding 
situations at work and may, hence, experience less job strain 1 year later than workers with a low active coping style (cf. [18, 27]). However, sometimes, stress-buffering effects of job resources might occur less often than what could have been expected on the basis of resource accessibility and workers' active coping style (i.e., high vs. low). More specifically, according to Warr's [28] concept of fit, workers with certain personal characteristics seek out and respond to jobs that offer more of these characteristics. If we apply this concept of fit to the current setting (i.e., workers who activate job resources to actively cope with job demands), it is plausible that workers will only activate available job resources if they have a personal characteristic (i.e., a high active coping style) that corresponds to the type of job resources concerned. In other words, the nature of coping may need to be specific to job resources to optimize the synergistic effect of high active coping style (cf. [21, 22]).

In line with the distinction made by Greenglass, Schwarzer, Jakubiec, Fiksenbaum, and Taubert [29], we defined three types of active coping styles: cognitive, emotional, and physical active coping styles. Each specific type of active coping style reflects the extent to which workers are likely to activate specific, corresponding types of job resources to actively cope with job demands (cf. [28]). For instance, workers with a high cognitive active coping style are more likely to use cognitive job resources than workers with a low cognitive active coping style. In a similar vein, workers with a high emotional active coping style are more likely to use emotional job resources than workers with a low emotional active coping style, whereas workers with a high physical active coping style are more likely to use physical job resources than workers with a low physical active coping style. Though some workers may score high on all three types of active coping styles, others may only score high on one or two specific types of active coping styles and may therefore only use job resources from one or two specific domains (e.g., cognitive or physical job resources) to actively cope with job demands. For this latter group of workers, stress-buffering effects of job resources from the third domain (i.e., emotional job resources) are less likely to occur. This brings us to the following hypotheses:

Hypothesis 2 Stress-buffering effects of job resources on the longitudinal relation between job demands and job strain are more likely to occur if workers have a high specific active coping style than if workers have a low specific active coping style.

Hypothesis 3 The synergistic effect of high specific active coping styles are more likely to occur if there is a match between specific types of job resources and specific types of active coping styles than if there is a non-match between specific types of job resources and specific types of active coping styles.

\section{Method}

Design

Data were collected among graduates from eight Belgian teacher training colleges and were obtained by a questionnaire survey that was conducted at the end of 2004 (time 1), the end of 2005 (time 2), and the end of 2006 (time 3). Questionnaires were sent to the workers' home addresses. Respondents participated on a voluntary basis and signed an informed consent at each measurement. Because the strain measures at time 3 differed from the strain measures at time 1 and time 2, it was decided to test our hypotheses by means of the first and second wave of the study. Active coping style, however, was only measured during the third and final wave of the study (the idea to examine the synergistic effect of matching active coping styles originated after the second wave of data collection), so that the final study group consisted of teachers who participated in all three waves. Because active coping style was not measured at time 1 , this person variable could not be examined as a continuous moderator and had to be examined as a dichotomous moderator instead (see data analysis).

\section{Participants}

The study group consisted of 317 teacher training graduates who worked as a teacher between 2004 and 2006. Of all graduates who were invited to participate in the study at time $1(N=7,092), 2,527$ returned the questionnaire (response rate $35.6 \%$ ). This moderate response rate can be attributed to undeliverable postal addresses, unemployment, and the length of the questionnaire. From the initial group of respondents, we selected the graduates who were currently working as a teacher $(N=1,116)$. At time 2,443 out of 1,116 graduates returned the questionnaire and were still working as a teacher. The final group consisted of 317 out of 443 graduates who were still working as a teacher when they filled out the active coping style scales at time 3.

The mean age in the study group was 26.4 years $(\mathrm{SD}=$ $5.6)$ and $78.5 \%$ were female. On average, participants had 4.1 years $(\mathrm{SD}=1.8)$ teaching experience, and $88.6 \%$ worked full-time [i.e., 20 to 30 teaching units $(1 \mathrm{unit}=50 \mathrm{~min}$ direct contact with pupils) per week]. Of all participants, $33.8 \%$ worked in primary education $(28.4 \%$ regular education and $5.4 \%$ special education), $56.6 \%$ worked in secondary 
education $(52.4 \%$ regular education and $4.2 \%$ special education), and $9.6 \%$ worked in other types of education.

A comparison of drop-outs [i.e., no participation at time 2 ('group A') or at time 3 ('group B')] with continuous participants [i.e., participation at time 1 and time 2 ('group $\mathrm{C}^{\prime}$ ), or at time 1 , time 2 , and time 3 ('group D')] showed that the data did not appear to suffer from serious selection problems. Specifically, using multiple logistic regression in which a dichotomous variable distinguishing participants who remained in the study from those who dropped out was included as the dependent variable (cf. [30]), attrition effects were found for cognitive job demands at time 1 ('group A' vs. 'group C', and 'group A' vs. 'group D'), and for physical job resources at time 1, and physical complaints at time 2 ('group B' vs. 'group D'). However, inspection of the respective mean scores revealed no healthy worker effect [31]. That is, it was shown that 'group A' $(M=3.88)$ experienced less cognitive demands at time 1 than 'group C' $(M=3.98)$ and 'group D' $(M=3.99)$. Further, 'group B' indicated that they had more physical job resources at time $1 \quad(M=3.44)$ and less physical complaints at time $2(M=1.66)$ than 'group D' $(M=3.24$ and $M=1.73$, respectively).

\section{Measures}

Independent variables included in this study were cognitive, emotional, and physical job demands (time 1), corresponding job resources (time 1), and corresponding active coping styles (time 3). Dependent variables were chosen from the same domain as demands, resources, and active coping styles, resulting in cognitive, emotional, and physical strain measured at time 1 and time 2. Table 1 shows the psychometric properties of the measures included as well as their zero-order correlations.

Job demands and job resources Cognitive, emotional, and physical job demands and job resources were assessed with the DISC questionnaire (DISQ 1.1, [32]), which has been used in other studies as well (e.g., [33, 34]). Items were scored on a 5-point frequency scale, ranging from 1 (never or very rarely) to 5 (very often or always).

The cognitive, emotional, and physical demands scales were measured with four, six, and five items, respectively. Example items of the respective demands scales are successively 'worker X will need to display high levels of concentration and precision at work', 'worker $\mathrm{X}$ will have to display emotions (e.g., towards clients, colleagues, or supervisors) that are inconsistent with his/her current feelings', and 'worker X will have to lift or move heavy persons or objects (more than $10 \mathrm{~kg}$ )'.

The cognitive, emotional, and physical resources scales were measured with five items each. Example items of the respective resources scales are successively 'worker X would have the opportunity to take a break when tasks require a lot of concentration', 'other people (e.g., clients, colleagues, or supervisors) would be a listening ear for worker X when he/she has faced a threatening situation', and 'worker X would receive help from others (e.g., clients, colleagues, or supervisors) in lifting or moving heavy persons or objects'.

Active coping styles Items assessing the three specific types of active coping styles were scored on a four-point agreement scale, ranging from 1 (totally disagree) to 4 (totally agree). Cognitive active coping style was measured with 11 items derived from the Reflective Coping Scale [29]. An example item is 'I tackle a problem by thinking about realistic alternatives'. Emotional active coping style was measured with five items derived from the Emotional Support Seeking Scale [29]. An example item is 'If I am depressed at work, I make an appeal to others (e.g., colleagues, supervisors, or clients) to help me feel better'. Physical active coping style was measured with four items based on the Instrumental Support Seeking Scale [29]. An example item is 'If my job requires many or sustained physical efforts, I ask help from others (e.g., colleagues or supervisor)'.

Strain Cognitive strain was defined as the lack of active learning, that is, the degree workers are enabled and stimulated to acquire new knowledge and skills. This cognitive construct was measured with three items that were derived from a scale developed by Taris, Kompier, de Lange, Schaufeli, and Schreurs [35]. An example item is 'In my job I can develop myself'. Items were scored on a four-point frequency scale, ranging from 1 [(almost) never] to 4 [(nearly) always]. To assist in the interpretation of the results, the signs of the respective parameter estimates have been reversed, such that high levels of active learning reflect cognitive strain. Emotional strain was assessed by an index of emotional exhaustion, which can be defined as a feeling of being emotionally worn out. This construct was measured with eight items derived from the Utrecht Burnout Scale that has been particularly designed for teachers [36]. An example item is 'I feel emotionally drained from my work'. Items were scored on a seven-point frequency scale, ranging from 0 (never) to 6 (always). Physical strain was assessed by an index of physical complaints. Physical complaints refer to neck, shoulder, back, and limbs problems in the last 6 months and were measured with four items derived from a scale developed by Hildebrandt and Douwes [37]. An example item is 'During the past 6 months, did you have trouble with your low back?'. The possible responses were 1 (no), 2 (sometimes), and 3 (yes). 


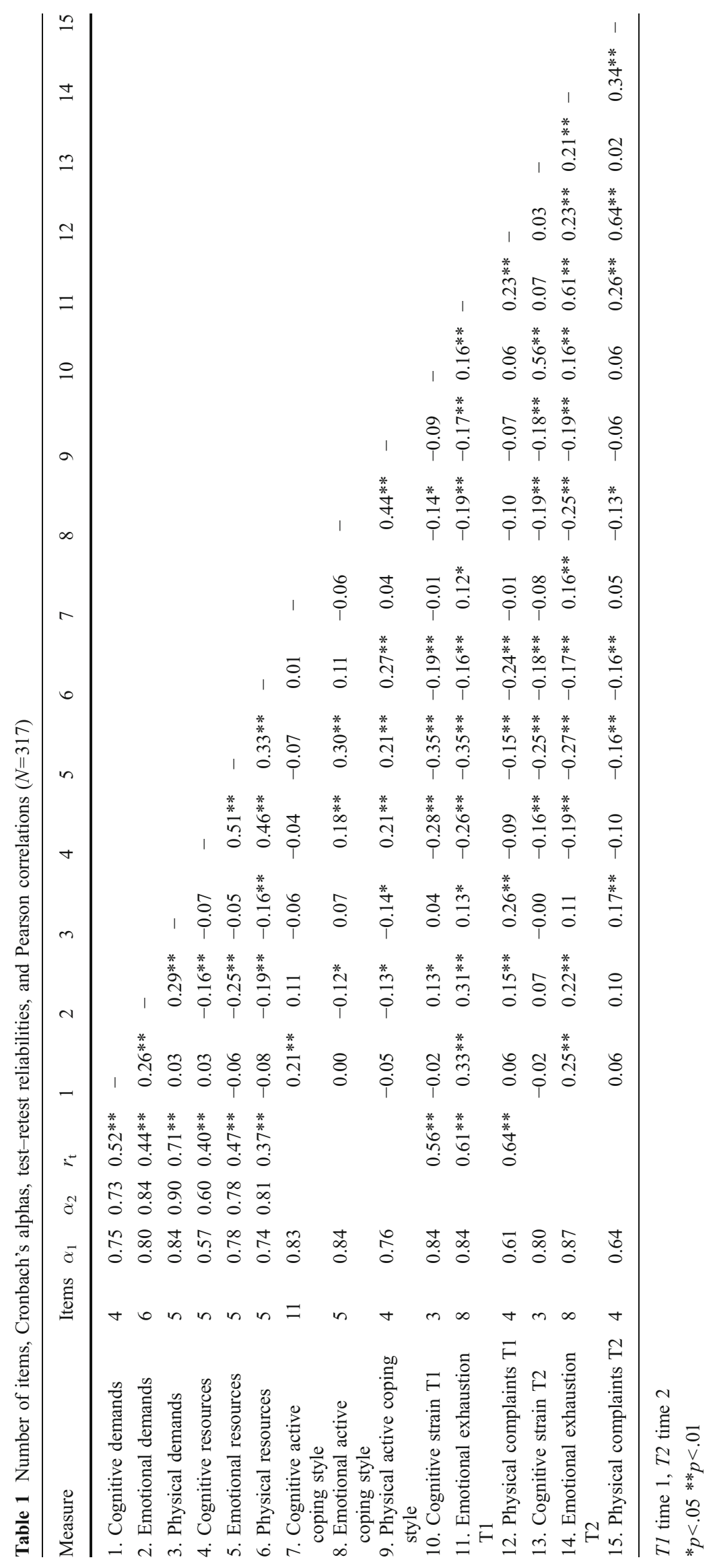




\section{Data Analysis}

We applied structural equation modeling (SEM) using LISREL 8.50 [38] to test for stress-buffering effects of job resources on the longitudinal relation between job demands and job strain. In addition, because active coping style was measured at time 3, multiple group analyses were used to test whether (a) any differences could be observed between workers with a low specific active coping style and workers with a high specific active coping style, and (b) the nature of coping must be specific to job resources to optimize the synergistic effect of high specific active coping styles. Specifically, three pairs of subgroups were created by dividing scores on each type of active coping style, using median split. Workers were categorized based on their score as either having a low specific active coping style (low score) or a high specific active coping style (high score) (cf. [39]). This resulted in different subgroups (i.e., two per coping style) of workers having a low cognitive active coping style $(N=164)$ and workers having a high cognitive active coping style $(N=143)$, workers having a low emotional active coping style $(N=147)$ and workers having a high emotional active coping style $(N=169)$, and workers having a low physical active coping style $(N=172)$ and workers having a high physical active coping style $(N=140)$.

Stress-buffering effects of job resources on the longitudinal relation between job demands and job strain were tested by examining multiplicative interaction terms between job demands and job resources (i.e., demands $\times$ resources) at time 1 in the prediction of job strain at time 2 . Because of the large number of interaction terms (nine in total), stressbuffering effects of job resources were tested by means of two separate analyses including either interaction terms between matching demands and resources, or interaction terms between non-matching demands and resources (see [26]). These two separate analyses were conducted in each subgroup, resulting in 12 SEM analyses in which we also controlled for age and gender, as well as for cognitive strain, emotional exhaustion, and physical complaints at time 1 .

According to Jaccard and Wan [40], multiple group analyses can be conducted for each pair of subgroups (i.e., low vs. high cognitive active coping style, low vs. high emotional active coping style, and low vs. high physical active coping style) by first estimating the parameters of the main terms and moderating terms in the different groups with no across-group constraints imposed (i.e., the main terms and interaction terms of both groups are assumed to be unequal). If the pooled chi-square of a particular pair of subgroups is non-significant, the parameters can be reestimated with across-group constraints imposed on all main terms and moderating terms (i.e., the main terms and interaction terms of both groups are assumed to be equal). A moderating effect of a particular type of active coping style is present if the pooled chi-square of the constrained model is significantly higher than the pooled chi-square of the unconstrained model. Because the residuals among our outcome variables at time 2 were allowed to correlate, the unconstrained models were fully saturated resulting in three pooled chi-squares of zero (which is non-significant). Next, we reestimated the parameters with across-group constraints imposed on all main terms and moderating terms, and calculated whether the pooled chi-squares of the constrained models significantly differed from zero (i.e., the pooled chi-square of the unconstrained models).

\section{Results}

Testing hypothesis 1 , results in Table 2 showed two significant two-way interactions between matching job demands and job resources in the prediction of job strain 1 year later. One twoway interaction showed a stress-buffering effect. Specifically, it was shown that a combination of high physical demands and high physical resources resulted in less emotional exhaustion 1 year later than a combination of high physical demands and low physical resources $(t=-3.15, p<.01)$. The other two-way interaction was not in the predicted direction. That is, a reversed interaction effect was found in which a combination of high cognitive demands and high cognitive resources led to more cognitive strain 1 year later than a combination of high cognitive demands and low cognitive resources $(t=2.25, p<.05)$.

In addition to the significant two-way interactions between matching demands and resources, one significant two-way interaction was found between non-matching demands and resources. More specifically, as shown in Table 3, a combination of high emotional demands and high physical resources resulted in less emotional exhaustion 1 year later than a combination of high emotional demands and low physical resources $(t=-2.25, p<.05)$.

To summarize, one out of nine (11.1\%) tested two-way interactions between matching demands and resources, and one out of $18(5.6 \%)$ tested two-way interactions between non-matching demands and resources showed a lagged stressbuffering effect of job resources. To determine whether the percentages were significantly different from each other, a $z$ test was conducted [41]. Contrary to hypothesis 1 , results of the $z$ test revealed that stress-buffering effects of job resources on the longitudinal relation between job demands and job strain were equally likely to occur in case of a match between specific types of job demands and job resources as in case of a non-match between specific types of job demands and job resources $(z=0.26 ; p=.80)$.

Testing hypothesis 2, results of the multiple group analyses showed that for each type of active coping style (i.e., cognitive, emotional, and physical active coping 
Table 2 Lagged structural equation models of cognitive strain, emotional exhaustion, and physical complaints with moderating terms of matching job demands and job resources for the total sample $(N=317)$

\begin{tabular}{|c|c|c|c|c|c|c|c|c|c|}
\hline & \multicolumn{3}{|c|}{ Cognitive strain $\mathrm{T} 2$} & \multicolumn{3}{|c|}{ Emotional exhaustion T2 } & \multicolumn{3}{|c|}{ Physical complaints T2 } \\
\hline & $B$ & SE & $t$ & $B$ & SE & $t$ & $B$ & SE & $t$ \\
\hline \multicolumn{10}{|l|}{ Control variables } \\
\hline Gender & -0.19 & 0.08 & $-2.27^{*}$ & 0.04 & 0.12 & 0.34 & 0.11 & 0.08 & 1.28 \\
\hline Age & -0.00 & 0.01 & -0.18 & 0.00 & 0.01 & 0.35 & 0.00 & 0.01 & 0.33 \\
\hline \multicolumn{10}{|l|}{ T1 outcome variables } \\
\hline Cognitive strain $\mathrm{T} 1$ & 0.50 & 0.05 & $10.07 * *$ & 0.04 & 0.07 & 0.63 & -0.03 & 0.05 & -0.54 \\
\hline Emotional exhaustion $\mathrm{T} 1$ & -0.02 & 0.04 & -0.58 & 0.49 & 0.05 & $9.09^{* *}$ & 0.13 & 0.04 & $3.33^{* *}$ \\
\hline Physical complaints $\mathrm{T} 1$ & -0.05 & 0.05 & -0.99 & 0.12 & 0.07 & 1.71 & 0.43 & 0.05 & $8.40^{* *}$ \\
\hline \multicolumn{10}{|l|}{ Demands and resources } \\
\hline Cognitive demands & -0.00 & 0.04 & -0.11 & 0.12 & 0.05 & $2.37 *$ & -0.01 & 0.04 & -0.24 \\
\hline Emotional demands & 0.03 & 0.04 & 0.85 & 0.06 & 0.05 & 1.15 & 0.00 & 0.04 & 0.00 \\
\hline Physical demands & -0.02 & 0.03 & -0.74 & -0.01 & 0.05 & -0.24 & 0.02 & 0.03 & 0.54 \\
\hline Cognitive resources & 0.04 & 0.04 & 1.11 & -0.01 & 0.06 & -0.19 & 0.03 & 0.04 & 0.88 \\
\hline Emotional resources & -0.05 & 0.04 & -1.21 & -0.02 & 0.06 & -0.38 & -0.04 & 0.04 & -1.14 \\
\hline Physical resources & -0.09 & 0.04 & $-2.37 *$ & -0.09 & 0.05 & -1.67 & -0.04 & 0.04 & -1.07 \\
\hline \multicolumn{10}{|l|}{ Moderating terms } \\
\hline Cognitive demands $\times$ cognitive resources & 0.08 & 0.03 & $2.25^{*}$ & 0.03 & 0.05 & 0.71 & 0.06 & 0.03 & 1.89 \\
\hline Emotional demands $\times$ emotional resources & -0.00 & 0.03 & -0.11 & 0.02 & 0.04 & 0.48 & 0.03 & 0.03 & 0.88 \\
\hline Physical demands $\times$ physical resources & -0.02 & 0.03 & -0.76 & -0.13 & 0.04 & $-3.15^{* *}$ & -0.01 & 0.03 & -0.34 \\
\hline
\end{tabular}

$B$ unstandardized coefficient, $S E$ standard error, $t$ t-statistic, $T 1$ time $1, T 2$ time 2

${ }^{*} p<.05 * * p<.01$

style), lagged moderating effects of job resources were equally likely to be found for teachers with a low active coping style as for teachers with a high active coping style. Specifically, testing moderating terms of matching demands and resources, no differences were found between workers with a low or high cognitive active coping style $\left(\Delta\right.$ pooled $\chi^{2}=$ 15.77, $d f=27, p=.96$ ), workers with a low or high emotional active coping style ( $\Delta$ pooled $\chi^{2}=0.95, d f=27, p=1.00$ ), and workers with a low or high physical active coping style ( $\Delta$ pooled $\left.\chi^{2}=4.10, d f=27, p=1.00\right)$. Similarly, testing moderating terms of non-matching demands and resources, no differences were found between workers with a low or high cognitive active coping style $\left(\Delta\right.$ pooled $\chi^{2}=23.49, d f=$ $36, p=.95)$, workers with a low or high emotional active coping style ( $\Delta$ pooled $\left.\chi^{2}=1.81, d f=36, p=1.00\right)$, and workers with a low or high physical active coping style ( $\Delta$ pooled $\left.\chi^{2}=4.79, d f=36, p=1.00\right)$. As we did not find any evidence for hypothesis 2 , there was no statistical rationale for testing hypothesis 3 .

\section{Discussion}

The current study aimed to expand earlier research on job stress by examining whether stress-buffering effects of job resources on the longitudinal relation between job demands and job strain (i.e., stressor-strain relations that developed within 1 year) are more likely to occur if (a) there is a match (rather than a non-match) between specific types of job demands and job resources (hypothesis 1), and (b) workers have a high specific active coping style rather than a low specific active coping style (hypothesis 2). In addition, it was hypothesized that the synergistic effect of high specific active coping styles occurs more often if there is a match (rather than a non-match) between specific types of job resources and specific types of active coping styles (hypothesis 3).

\section{Matching Hypothesis}

Contrary to the matching hypothesis (hypothesis 1), results showed that stress-buffering effects of job resources on the longitudinal relation between job demands and job strain were equally likely to occur in case of a match between specific types of demands and resources as in case of a nonmatch between specific types of demands and resources. In addition, lagged stress-buffering effects of job resources were only found if physical resources were involved, whereas no effects were found containing a cognitive component (i.e., cognitive demands, cognitive resources, 
Table 3 Lagged structural equation models of cognitive strain, emotional exhaustion, and physical complaints with moderating terms of nonmatching job demands and job resources for the total sample $(N=317)$

\begin{tabular}{|c|c|c|c|c|c|c|c|c|c|}
\hline & \multicolumn{3}{|c|}{ Cognitive strain $\mathrm{T} 2$} & \multicolumn{3}{|c|}{ Emotional exhaustion T2 } & \multicolumn{3}{|c|}{ Physical complaints T2 } \\
\hline & $B$ & SE & $t$ & $B$ & SE & $t$ & $B$ & SE & $t$ \\
\hline \multicolumn{10}{|l|}{ Control variables } \\
\hline Gender & -0.19 & 0.08 & $-2.30^{*}$ & 0.09 & 0.12 & 0.74 & 0.09 & 0.08 & 1.09 \\
\hline Age & -0.00 & 0.01 & -0.68 & 0.00 & 0.01 & 0.12 & 0.00 & 0.01 & 0.23 \\
\hline \multicolumn{10}{|l|}{ T1 outcome variables } \\
\hline Cognitive strain $\mathrm{T} 1$ & 0.48 & 0.05 & $9.67 * *$ & 0.03 & 0.07 & 0.45 & -0.05 & 0.05 & -1.05 \\
\hline Emotional exhaustion $\mathrm{T} 1$ & -0.02 & 0.04 & -0.58 & 0.49 & 0.05 & $9.00 * *$ & 0.12 & 0.04 & $3.19 * *$ \\
\hline Physical complaints $\mathrm{T} 1$ & -0.04 & 0.05 & -0.82 & 0.11 & 0.07 & 1.49 & 0.44 & 0.05 & $8.61 * *$ \\
\hline \multicolumn{10}{|l|}{ Demands and resources } \\
\hline Cognitive demands & -0.02 & 0.04 & -0.65 & 0.11 & 0.05 & $2.07 *$ & -0.01 & 0.04 & -0.28 \\
\hline Emotional demands & 0.04 & 0.04 & 1.12 & 0.06 & 0.05 & 1.22 & 0.00 & 0.04 & -0.12 \\
\hline Physical demands & -0.03 & 0.03 & -0.89 & 0.00 & 0.05 & -0.06 & 0.01 & 0.03 & 0.45 \\
\hline Cognitive resources & 0.04 & 0.04 & 1.10 & -0.01 & 0.06 & -0.25 & 0.03 & 0.04 & 0.71 \\
\hline Emotional resources & -0.05 & 0.04 & -1.36 & -0.04 & 0.06 & -0.69 & -0.05 & 0.04 & -1.32 \\
\hline Physical resources & -0.11 & 0.04 & $-2.88 * *$ & -0.08 & 0.05 & -1.41 & -0.05 & 0.04 & -1.39 \\
\hline \multicolumn{10}{|l|}{ Moderating terms } \\
\hline Cognitive demands $\times$ emotional resources & 0.01 & 0.03 & 0.42 & 0.04 & 0.05 & 0.85 & -0.02 & 0.03 & -0.48 \\
\hline Cognitive demands $\times$ physical resources & 0.05 & 0.04 & 1.23 & 0.02 & 0.06 & 0.43 & 0.07 & 0.04 & 1.90 \\
\hline Emotional demands $\times$ cognitive resources & 0.02 & 0.03 & 0.54 & 0.02 & 0.05 & 0.45 & 0.06 & 0.03 & 1.74 \\
\hline Emotional demands $\times$ physical resources & -0.05 & 0.03 & -1.32 & -0.11 & 0.05 & $-2.25^{*}$ & -0.02 & 0.03 & -0.49 \\
\hline Physical demands $\times$ cognitive resources & 0.04 & 0.04 & 1.11 & -0.04 & 0.05 & -0.83 & -0.03 & 0.04 & -0.75 \\
\hline Physical demands $\times$ emotional resources & 0.06 & 0.03 & 1.66 & 0.04 & 0.05 & 0.83 & 0.03 & 0.03 & 0.97 \\
\hline
\end{tabular}

$B$ unstandardized coefficient, $S E$ standard error, $t$ t-statistic, $T 1$ time 1, T2 time 2

${ }^{*} p<.05 * * p<.01$

or cognitive strain). This study is therefore somewhat inconsistent with other longitudinal studies on the relation between demands, resources, and strain, which showed much stronger evidence for the matching hypothesis [26, 42]. One explanation for the current findings may be that our study group consisted of beginning teachers who still needed to develop adequate coping strategies to deal with high job demands (cf. [43]). That is, the beginning teachers in our study group may still have needed to learn what kind of job resources they had to employ to realize an optimal match between job demands and job resources. In any case, to put the current findings in the right perspective, more longitudinal studies on the matching hypothesis are badly needed.

\section{Matching Active Coping Styles}

Contrary to hypothesis 2 , results revealed that neither type of active coping style interacted with job resources to moderate the longitudinal relation between job demands and job strain. Because lagged moderating effects of job resources were equally likely to be found for teachers with a low specific active coping style as for teachers with a high specific active coping style, there was no statistical rationale for testing hypothesis 3 .

One explanation why lagged moderating effects of job resources were equally likely to be found for workers with a low specific active coping style as for workers with a high specific active coping style, could be that job characteristics (i.e., demands and resources) are of more importance to the job stress process than personal characteristics (i.e., specific active coping styles). Though it has been argued that personal characteristics are particularly likely to moderate the linkages between job conditions and strain [13], moderating effects of coping style have not always been demonstrated (e.g., [44]). An alternative explanation may be that the mere perception that one has sufficient job resources to cope with job stressors (e.g., colleagues who can provide support) may already offset the impact of job demands (cf. [5]). Perhaps workers with a low specific active coping style did not necessarily need to activate available job resources in order to mitigate (or prevent) the adverse impact of high job demands on their health and well-being 1 year later. In addition, because active coping 
style was examined as a dichotomous moderator, power problems might explain why specific active coping styles did not make a significant contribution to the prediction of job strain. Finally, a better focus for research might be specific active coping behaviors as they occur in specific demanding episodes at work. Because measurements of coping close to when coping happens provide some of the most accurate assessments of coping [45], future research could use hourly and daily reports of coping to examine whether specific active coping behaviors interact with specific job resources to buffer the relation between specific demanding episodes at work and job strain. If such effects are found, the current lack of support for interactions between specific demands, resources, and active coping could be explained by the measures used in this study to assess coping.

\section{Study Limitations and Implications}

A key limitation of the current study is that it included a homogeneous group of beginning teachers, which-given the moderate response rate-might not be representative for the population of teacher training graduates who were invited to participate in the study. Because this group poses questions about the study's generalizability to the teaching profession in general as well as other service jobs, future research could focus on more heterogeneous groups. A second limitation of this study is that some findings may not be fully reliable due to the somewhat lower alpha (57) of the cognitive resource scale.

From a theoretical point of view, the current findings suggest that, in order to show stress-buffering effects of job resources on the longitudinal relation between job demands and job strain, it makes no difference whether or not specific types of job resources are matched to specific types of job demands. In addition, the findings emphasize the importance of job rather than personal characteristics [46]. Specifically, results showed that for each type of active coping style, two-way interactions between specific types of job demands and job resources had similar lagged effects on job strain for workers with a low specific active coping style as for workers with a high specific active coping style. Hence, to show stress-buffering effects of job resources on the longitudinal relation between job demands and job strain, it seems to make no difference whether or not individual differences in specific active coping styles are taken into account.

The current findings could be of importance to educational practice as well, as there is a high attrition rate, especially among beginning teachers [47]. Those who leave the teaching profession usually do so within the first 5 years [48]. Further, school teaching is generally regarded as a highly stressful profession [49]. Burnout, for instance, is a major problem among teachers, and may seriously affect the achievement of educational goals even before attrition is at stake [50, 51]. In this study, it was shown that the adverse lagged effects of physical and emotional job demands on emotional exhaustion can both be diminished by physical job resources. However, given the existing body of empirical evidence for the matching hypothesis [8] and the fact that the current findings did not suggest that non-matching job resources are more functional stress buffers than matching job resources, it is recommended that employers do not only give priority to physical job resources to arm teachers against these job demands, but also try to make matching emotional job resources easily accessible to all workers. For instance, when teachers need to deal with job-inherent emotions (e.g., being angry with rude pupils) and/or organizationally desired emotions (e.g., staying calm in front of a class), employers could provide emotional support, or stimulate emotional support among colleagues (e.g., a listening ear during breaks or work meetings). In addition to job redesign interventions in personnel selection, teachers could be selected based on personal characteristics that strengthen their immunity to job strain. The current findings suggest, however, that there is no need to address teachers' specific active coping styles, as these personal characteristics do not seem to affect the investment of available job resources during stressful situations at work.

To conclude, results in this longitudinal survey study did support neither the matching hypothesis, nor the moderating effect of specific (matching) active coping styles on the stressbuffering effect of job resources. However, since the results were somewhat inconsistent with previous findings on the matching hypothesis [26, 42], and previous research has shown mixed results with respect to the moderating effect of coping (see e.g., [18, 44]), one should be cautious drawing any firm, generalizable conclusions with respect to the matching hypothesis and the moderating effect of specific (matching) active coping styles. Therefore, further longitudinal research among both beginning and experienced teachers as well as in multi-occupation groups is highly recommended.

Acknowledgment This study was supported by the Special Research Fund at Ghent University (BOF 01J00405).

Open Access This article is distributed under the terms of the Creative Commons Attribution Noncommercial License which permits any noncommercial use, distribution, and reproduction in any medium, provided the original author(s) and source are credited.

\section{References}

1. Demerouti E, Bakker AB, Nachreiner F, Schaufeli WB. The job demands-resources model of burnout. J Appl Psychol. 2001;86 (3):499-512.

2. Bakker AB, Demerouti E. The job demands-resources model: state of the art. J Managerial Psychol. 2007;22(3):309-28. 
3. Karasek R, Theorell T. Healthy work stress, productivity, and the reconstruction of working life. New York: Basic Books; 1990.

4. Siegrist J. Adverse health effects of high-effort/low-reward conditions. J Occup Health Psychol. 1996;1:27-41.

5. Cohen S, Wills TA. Stress, social support, and the moderating hypothesis. Psychol Bull. 1985;98:310-57.

6. Cutrona CE, Russell DW. Type of social support and specific stress: toward a theory of optimal matching. In: Sarason BR, Sarason IG, Pierce GR, editors. Social support: an interactional view. New York: Wiley; 1990. p. 319-66.

7. Cohen S, McKay G. Social support, stress and the buffering hypothesis: a theoretical analysis. In: Baum A, Taylor SE, Singer JE, editors. Handbook of psychology and health. Hillsdale: Erlbaum; 1984. p. 253-67.

8. de Jonge J, Dormann C, van den Tooren M. The demand-induced strain compensation model: renewed theoretical considerations and empirical evidence. In: Näswall K, Hellgren J, Sverke M, editors. The individual in the changing working life. Cambridge: Cambridge University; 2008. p. 67-87.

9. Taris T, Kompier M. Challenges of longitudinal designs in occupational health psychology. Scand J Work Environ Health. 2003;29:1-4.

10. de Jonge J, Dormann C, Janssen PPM, Dollard MF, Landeweerd JA, Nijhuis FJN. Testing reciprocal relationships between job characteristics and psychological well-being: a cross-lagged structural equation model. J Occup Organ P sychol. 2001;74:2946

11. de Lange AH, Taris TW, Kompier MAJ, Houtman ILD, Bongers PM. "The very best of the millenium": longitudinal research and the demand-control-(support) model. J Occup Health Psychol. 2003;8(4):282-305.

12. de Lange AH, Taris TW, Kompier MAJ, Houtman ILD, Bongers PM. The relationships between work characteristics and mental health: examining normal, reversed and reciprocal relationships in a 4-wave study. Work Stress. 2004;18(2):14966.

13. Cooper CL, Dewe PJ, O'Driscoll MP. Organizational stress: a review and critique of theory, research, and applications. Thousand Oaks: Sage; 2001.

14. Aspinwall LG, Taylor SE. A stitch in time: self-regulation and proactive coping. Psychol Bull. 1997;121(3):417-36.

15. Lazarus RS. Emotion and adaptation. Oxford: Oxford University Press; 1991.

16. Latack JC. Coping with job stress: measures and future directions of scale development. J Appl Psychol. 1986;71:377-85.

17. Pienaar J. Skeleton key or siren song: is coping the answer to balancing work and well-being? In: Näswall K, Hellgren J, Sverke $\mathrm{M}$, editors. The individual in the changing working life. Oxford: Cambridge University; 2008. p. 235-57.

18. de Rijk AE, Le Blanc PM, Schaufeli WB, de Jonge J. Active coping and need for control as moderators of the job demandcontrol model: effects on burnout. J Occup Organ $\mathrm{P}$ sychol. 1998;71:1-18.

19. Shimazu A, de Jonge J, Irimajiri H. Lagged effects of active coping within the demand-control model: a three-wave panel study among Japanese employees. Int J Behav Med. 2008;15:44 53

20. Daniels K, de Jonge J. Match making and match breaking: the nature of match within and around job design. J Occup Organ P sychol. 2010;83(1):1-16

21. Daniels K, Harris C, Briner RB. Linking work conditions to unpleasant affect: cognition, categorisation and goals. J Occup Organ P sychol. 2004;77:343-63.

22. Frese M. Social support as a moderator of the relationship between work stressors and psychological dysfunctioning: a longitudinal study with objective measures. J Occup Health Psychol. 1999;4:179-92.

23. Sargent LD, Terry DJ. The effects of work control and job demands on employee adjustment and work performance. J Occup Organ P sychol. 1998;71:219-36.

24. Hockey GRJ. Work environments and performance. In: Chmiel $\mathrm{N}$, editor. Introduction to work and organizational psychology: a European perspective. Oxford: Blackwell; 2000. p. $206-30$

25. de Jonge J, Dormann C. The DISC model: demand-induced strain compensation mechanisms in job stress. In: Dollard MF, Winefield HR, Winefield AH, editors. Occupational stress in the service professions. London: Taylor \& Francis; 2003. p. $43-74$.

26. de Jonge J, Dormann C. Stressors, resources, and strains at work: a longitudinal test of the triple match principle. J Appl Psychol. 2006;91(5):1359-74.

27. Schaufeli WB. Coping with job stress. In: Smelser NJ, Baltes PB, editors. The international encyclopedia of the social and behavioral sciences. Oxford: Elsevier; 2001. p. 7983-7.

28. Warr P. Work, unemployment and mental health. Oxford: Clarendon; 1987.

29. Greenglass E, Schwarzer R, Jakubiec SD, Fiksenbaum L, Taubert S. The Proactive Coping Inventory (PCI): a multidimensional research instrument. paper presented at the 20th International Conference of the STAR (Stress and Anxiety Research Society). Poland: Cracow; 1999.

30. Goodman JS, Blum TC. Assessing the non-random sampling effects of subject attrition in longitudinal research. J Manage. 1996;22(4):627-52.

31. Zapf D, Dormann C, Frese M. Longitudinal studies in organizational stress research: a review of the literature with reference to methodological issues. J Occup Health Psychol. 1996;1(2):14569.

32. de Jonge J, Dormann C, van Vegchel N, von Nordheim T, Dollard M, Cotton S. DISQ 1.1: De DISC Vragenlijst Nederlandse Versie 1.1 [DISQ 1.1: The DISC Questionnaire Dutch Version 1.1]. Eindhoven: Eindhoven University of Technology; 2004

33. van den Tooren $\mathrm{M}$, de Jonge J. Managing job stress in nursing: what kind of resources do we need? J Adv Nurs. 2008;63(1):7584.

34. Van de Ven B, Vlerick P, de Jonge J. The interplay of job demands, job resources and cognitive outcomes in informatics. Stress Health. 2008;24:375-82.

35. Taris TW, Kompier MAJ, de Lange AH, Schaufeli WB, Schreurs PJG. Learning new behaviour patterns: a longitudinal test of Karasek's active learning hypothesis among Dutch teachers. Work Stress. 2003;17(1):1-20.

36. Schaufeli WB, van Dierendonck D. Utrechtse Burnout Schaal (UBOS): Handleiding [Utrecht Burnout Scale; Manual]. Lisse: Swets \& Zeitlinger; 2001

37. Hildebrandt VH, Douwes M. Lichamelijke Belasting en Arbeid: Vragenlijst Bewegingsapparaat [Physical demands and work: motion questionnaire]. Voorburg: Dictoraat-Generaal van de Arbeid; 1991

38. Jöreskog KG, Sörbom D. LISREL 8: user's reference guide. Chicago: Scientific Software International; 1996.

39. van Dick R, Wagner U. Stress and strain in teaching: a structural equation approach. Br J Educ Psychol. 2001;71:24359.

40. Jaccard J, Wan CK. Lisrel approaches to interaction effects in multiple regression. Thousand Oaks: Sage; 1996.

41. Moore DS, McCabe GP. Introduction to the practice of statistics. 3rd ed. New York: W. H. Freeman and Company; 1999. 
42. Chrisopoulos S, Dollard MF, Winefield AH, Dormann C. Increasing the probability of finding an interaction in workstress research: a two wave longitudinal test of the triple-match principle. J Occup Organ P sychol. 2010;83(1):17-37.

43. Le Maistre C, Paré A. Whatever it takes: how beginning teachers learn to survive. Teach Teach Educ. 2010;26:559-64.

44. Edwards JR, Baglioni AJ, Cooper CL. Stress, type-A, coping, and psychological and physical symptoms: a multi-sample test of alternative models. Hum Relat. 1990;43(10):919-56.

45. Todd M, Tennen H, Carney MA, Armeli S, Affleck G. Do we know how we cope? Relating daily coping reports to global and time-limited retrospective assessments. J Pers Soc Psychol. 2004;86(2):310-9.

46. Cox T. Stress. London: Macmillan; 1978.
47. Macdonald D. Teacher attrition: a review of literature. Teach Teach Educ. 1999;15:835-48.

48. Kersaint G, Lewis J, Potter R, Meisels G. Why teachers leave: factors that influence retention and resignation. Teach Teach Educ. 2007;23:775-94.

49. Howard S, Johnson B. Resilient teachers: resisting stress and burnout. Soc Psychol Educ. 2004;7:399-420.

50. Guglielmi RS, Tatrow K. Occupational stress, burnout, and health in teachers: a methodological and theoretical analysis. Rev Educ Res. 1998;68(1):61-99.

51. Stoeber J, Rennert D. Perfectionism in school teachers: relations with stress appraisals, coping styles, and burnout. Anxiety Stress Coping. 2008;21(1):37-53. 